\title{
Electron Transfer Reaction Of Butane -1,3-Diol And Cr(VI) In Aqueous Acidic Medium
}

\author{
S. O. Idris*, J. F. Iyun and E. B. Agbaji \\ Department of Chemistry Ahmadu Bello University, Zaria, Nigeria.
}

\begin{abstract}
Kinetic and mechanistic studies of electron transfer reaction of butane-1,3-diol and $\mathrm{Cr}(\mathrm{VI})$ ion in aqueous acidic medium have been carried out in aqueous medium at $27 \pm 1{ }^{\circ} \mathrm{C}, I=1.0 \mathrm{~mol} \mathrm{dm}{ }^{-3}(\mathrm{NaCl}),\left[\mathrm{H}^{+}\right]$ $=0.5 \mathrm{~mol} \mathrm{dm}^{-3}(\mathrm{HCl})$. The reaction was inhibited by added anions and showed negative salt effect. Spectroscopic investigations confirmed that precursor complex formation did not precede the electron transfer step. Interpretation of these observations suggest that the reactions most likely occur by the outersphere mechanism
\end{abstract}

\section{INTRODUCTION}

The oxidation of diols other than 1,2-diols by transition metal ions and their complexes has received little attention. An increased interest in these reactions was noticed after the oxidation of propane-1,3-, butane-1,3- and butane1,4 -diols by quinquivalent vanadium had been reported ${ }^{1}$. This interest was latter extended to the oxidation of some of these and other diols by $\mathrm{Ce}(\mathrm{IV})$ in two different acid media ${ }^{2-4}$ and aquomanganese(III) ions in perchloric acid medium 5 .

Convincing arguments have been advanced to support the formation of intermediate complexes containing both chelate and unidentate ligands in the above electron transfer reactions ${ }^{1,3}-10$. However, on the basis of the observed disparity between the rates of oxidation of these substrates and the energies of activation, the operation of inner or outersphere mechanism could not be confirmed .This has aroused our interest in probing the electron transfer reaction of the title reaction with a view to assigning a mechanistic pathway.

\section{EXPERIMENTAL}

All the reagents used were of analytical grade and were used without further purification. Standard solution of butane-1,3-diol (BDH) hereafter referred to as diol was prepared before use. Sodium dichromate (BDH) solution was prepared with distilled water and standardised titrimetrically ${ }^{11}$. Standard stock solutions of sodium chloride, sodium ethanoate and sodium methanoate were prepared and used to investigate the effect of added anions on reaction rate Stock solution of $\mathrm{HCl}(\mathrm{M} \& \mathrm{~B})$ was standardised titrimetrically and used to study the effect of $\mathrm{H}^{+}$on reaction rate .

The stoichiometry of the reaction was determined by spectrophotometric titration using the mole ratio method. The $\left[\mathrm{Cr}_{2} \mathrm{O}_{7}{ }^{2-}\right]$ was kept constant at $0.007 \mathrm{M}$ and concentrations of diol varied between $0.001 \mathrm{M}$ and $0.014 \mathrm{M}$ while maintaining $\left[\mathrm{H}^{+}\right]$and ionic strength (I) constant. These mixtures were allowed to stand 
until the repeated measurements of absorbances at $580 \mathrm{~nm} \quad\left(\lambda_{\max }\right)$ were constant. The stoichiometry was evaluated from the plot of absorbance versus [diol].

Using a Corning Colorimeter 253, the $\lambda_{\max }$ of the reaction product in aqueous solution was determined to be $580 \mathrm{~nm}$. Having certified that neither of the reactants absorbed significantly at this wavelength, kinetic measurements were conducted at this wavelength by monitoring the increase in absorbance of the mixtures as the reaction progressed. All kinetic measurements were carried out under pseudo-first order condition with diol concentration in excess over the dichromate ion concentration.

The effect of acid on the rate of the reaction was investigated in the range of $0.4 \leq\left[\mathrm{H}^{+}\right] \leq 0.8 \mathrm{~mol} \mathrm{dm}^{-3}$ while the concentrations of diol and dichromate ions were kept constant at 0.708 and 0.01 mol $\mathrm{dm}^{-3}$ respectively. The stoichiometric amounts of diol and $\mathrm{Cr}_{2} \mathrm{O}_{7}{ }^{2-}$ were reacted at $\left[\mathrm{H}^{+}\right]=0.6 \mathrm{~mol} \mathrm{dm}^{-}$ 3 and the product obtained after repeated extraction with diethylether was subjected to conventional functional group tests ${ }^{12}$ and comparative thin layer chromatographic analyses.

\section{RESULTS AND DISCUSSION}

The product extract formed crystals with 2,4-dinitrophenylhydrazine indicating the presence of carbonyl group. Further test for aldehydic functional group using Tollen's reagent and Fehling solution gave positive results The colour of the product solution at $\lambda_{\max }$ $(580 \mathrm{~nm})$ was blue-green and indicated the presence of $\mathrm{Cr}^{3+}$ in the mixture.

Each of butane-1,3-diol and the ether product was spotted on prepared tlc plates using petroleum ether and ethyl acetate (3:2); n-butanol, acetic acid and water $(4: 1: 5)$ mixtures as mobile phases. The spots were located by irradiation of the plate with ultraviolet light. The product moved as a single spot but butane-1,3-diol did not move at all from the base line. This ruled out the presence of butane-1,3-diol in the extract. Also about $2 \mathrm{~cm}^{3}$ of the product extract was tested for the presence of free $-\mathrm{OH}$ group by reacting it with ammonium ceric nitrate solution ${ }^{13}$. Absence of red colour indicated that the two $-\mathrm{OH}$ groups in the reductant were oxidized .

The result of the stoichiometric studies indicated 1:1 stoichiometry. The equation for the reaction can therefore be written as:

$\mathrm{CH}_{2} \mathrm{OHCH}_{2} \mathrm{CH}(\mathrm{OH}) \mathrm{CH}_{3}+\mathrm{Cr}_{2} \mathrm{O}_{7}^{2-}+\mathrm{H}^{+}$
$\rightarrow$ products $\ldots \ldots \ldots \ldots \ldots \ldots \ldots \ldots \ldots . . . \ldots \ldots \ldots$

Pseudo-first order plots of $\log \left(\mathrm{A}_{\infty}\right.$ - $\left.A_{t}\right)$ versus reaction time for these reactions were linear for more than $80 \%$ extent of the reaction $\left(\mathrm{A}_{\infty}\right.$ and $\mathrm{A}_{t}$ are the absorbances of the product at the end of the reaction and time $t$ respectively). The linearity of these plots is an indication that the reaction is first order with respect to $\mathrm{Cr}(\mathrm{VI})$. The pseudo first order rate constants $\left(\mathrm{k}_{1}\right)$ were determined from the slopes of these plots while the second order rate constants were evaluated as $\mathrm{k}_{2}=\mathrm{k}_{1} /$ [diol]. The invariance of $\mathrm{k}_{2}$ as shown in Table 1 over the concentration range investigated for the reductant also shows that the reaction with respect to [diol] is first order. At constant $\left[\mathrm{H}^{+}\right]$the rate law is:

$$
\frac{1}{2} \frac{d\left[C r^{3+}\right]}{d t}=k_{2}[\text { bu tan ediol }][\operatorname{Cr}(V I)] \ldots \ldots
$$

The order of one in the oxidant and reductant concentrations in this study conforms with that already reported for the reaction between butane-1,4-diol and 12-tungstocobaltate(III) anion in aqueous 
perchloric acid medium ${ }^{14}$ and leucomalachite green with $\mathrm{Cr}(\mathrm{VI})$ in hydrochloric acid aqueous medium ${ }^{15}$.

The result in Table 1 shows that the rate of the reaction increased with increase in acid concentration. The acid dependence rate constant $\mathrm{k}_{2}$ is given as:

$$
\mathrm{k}_{2}=\mathrm{a}\left[\mathrm{H}^{+}\right]
$$

$$
\mathrm{a}=1.56 \times 10^{-2} \mathrm{dm}^{6} \mathrm{~mol}^{-2} \mathrm{~s}^{-1} ;
$$

substituting (3) into equation (2),

the rate of the reaction becomes:

$\frac{1}{2} \frac{d\left[\mathrm{Cr}^{3+}\right]}{d t}=a\left[H^{+}\right][$bu tan ediol $][\mathrm{Cr}(\mathrm{VI})]$
The nature of acid dependence observed implies that there is a rapid equilibrium between protonated and unprotonated forms of the oxidant prior to the rate determining step and only protonated form is reactive. This observation is expected for $\mathrm{Cr}_{2} \mathrm{O}_{7}{ }^{2-}$ as the equilibria below have been established for aqueous solution of dichromate ions ${ }^{15-}$ 19

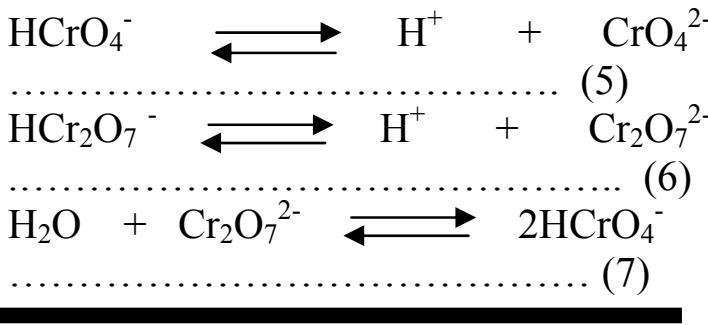

as the intervention of negatively charged However, of all the ions involving $\mathrm{Cr}(\mathrm{VI})$, the only species present in large concentrations in solution of this dilute mineral acid are $\mathrm{HCrO}_{4}^{-}$and $\mathrm{Cr}_{2} \mathrm{O}_{7}{ }^{2-}$. These ions are in equilibrium with each other according to equation (7). $\mathrm{HCrO}_{4}{ }^{-}$ has been shown to be predominant and the only active oxidizing species of these two species ${ }^{15-19}$.

The rate of the reaction was found (Table 1) to decrease with increase in ionic strength of the reaction medium in the range $0.6 \leq \mathrm{I} \leq 1.2 \mathrm{~mol} \mathrm{dm}^{-3}$ $(\mathrm{NaCl})$. The negative salt effect is an indication that the rate determining step involves oppositely charged ions ${ }^{20,21}$. Added methanoate and ethanoate ions retarded the rate of the reaction. This suggests that substitution of the reactant into the inner co-ordination shell of $\mathrm{Cr}$ centre did not precede electron transfer. The inhibition of the reaction by the anions could be due to coloumbic effect ions between oppositely charged reactants in the activated complex leads to repulsion of the reactants and hence a decrease in reaction rate.

The result of the spectrophotometric measurement showed no shift in $\lambda_{\max }$ from $580 \mathrm{~nm}$ when the absorbance of the reaction mixture was monitored at different wavelengths one minute after mixing. Similar observation has been reported for the reaction between butane-1,4-diol and 12tungstocobaltate(III) anion in perchloric acid medium ${ }^{14}$. This lends support to the conclusion that formation of an innersphere type of intermediate complex is not favoured in this investigation or that the formation constant for such intermediate is negligibly small.

On the basis of the results obtained the following scheme is proposed for the reaction. 

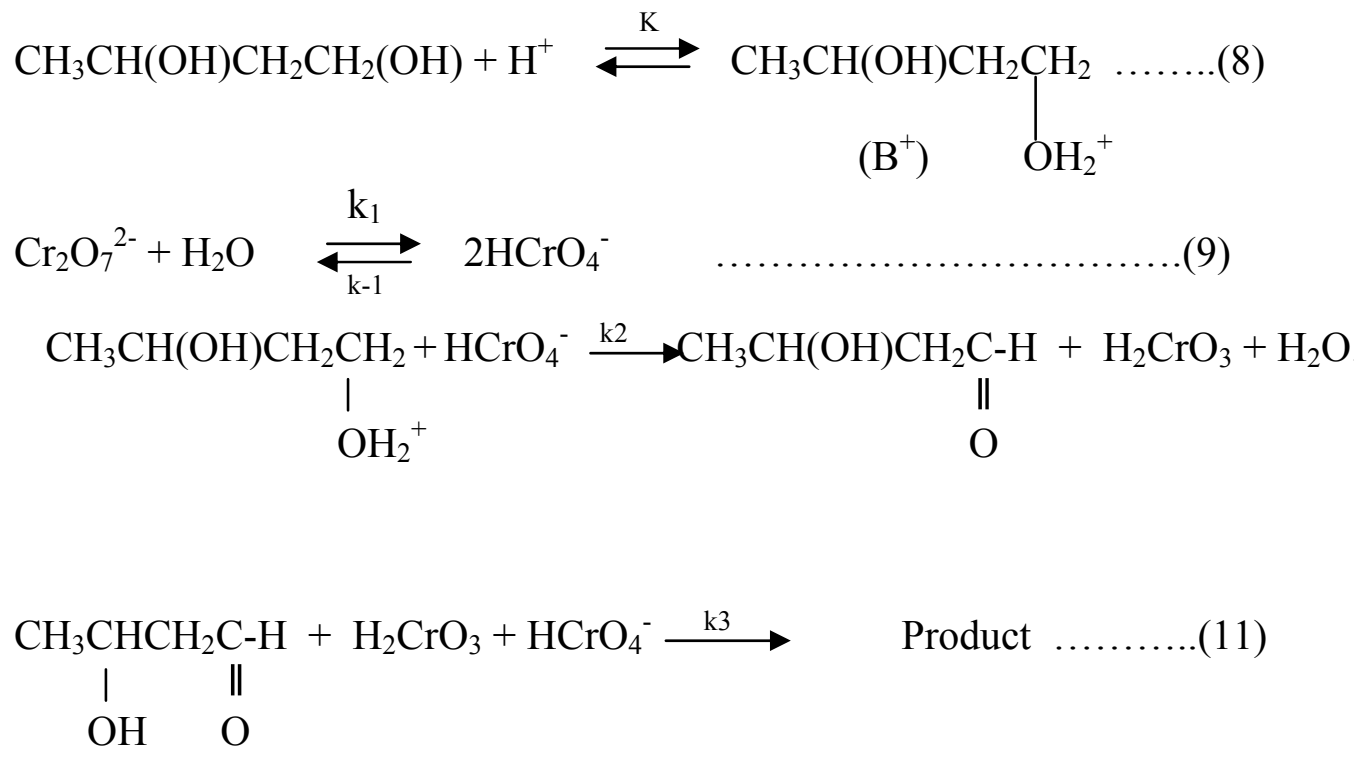

The rate law according to this scheme leads to the following expression

Rate $=\mathrm{k}_{2}\left[\mathrm{~B}^{+}\right]\left[\mathrm{HCrO}_{4}^{-}\right]$

But $\left[\mathrm{B}^{+}\right]=\mathrm{K}\left[\mathrm{CH}_{3} \mathrm{CH}(\mathrm{OH}) \mathrm{CH}_{2} \mathrm{CH}_{2}(\mathrm{OH})\right]\left[\mathrm{H}^{+}\right]$

Substitution of equation (13) into (12) gives

Rate $=\mathrm{k}_{2} \mathrm{~K}\left[\mathrm{CH}_{3} \mathrm{CH}(\mathrm{OH}) \mathrm{CH}_{2} \mathrm{CH}_{2}(\mathrm{OH})\right]\left[\mathrm{HCrO}_{4}^{-}\right]\left[\mathrm{H}^{+}\right]$

This is analogous to equation (4) where $\mathrm{a}=\mathrm{k}_{2} \mathrm{~K}$

In trying to assign mechanistic pathway for this reaction the following points have be considered: The negative result of polymerization test suggests the absence of free radical intermediate in the reaction or the equilibrium constant for the formation of such radicals can be assumed to be negligible. The inhibition of the reaction by the addition of anions is an indication that reaction probably occur through outersphere pathway. The absence of spectrophotometric and kinetic evidences for the presence of

intermediate suggests that the formation constants for existence of such intermediates, if present, must be very small. The zero intercept obtained in the Lineweaver-Burk modified MichaelisMenten plot $^{22,23}$ also indicates that intermediates with appreciable equilibrium constants are very unlikely in this reaction. This suggests that binuclear complex intermediate of inner sphere type is not important in this reaction.

Based on the above evidences, an outersphere mechanistic pathway is proposed for the title reaction. 
Table 1: Second order rate constants for the oxidation of butane-1,3-diol by $\mathrm{Cr}_{2} \mathrm{O}_{7}{ }^{2-}$ in aqueous $\mathrm{HCl}$ medium at $\left[\mathrm{Cr}_{2} \mathrm{O}_{7}{ }^{2-}\right]=0.01 \mathrm{~mol} \mathrm{dm}^{-3}$, $\lambda_{\text {max }}=580 \mathrm{~nm}$ and $\mathrm{T}=27 \pm 1^{\circ} \mathrm{C}$

\begin{tabular}{llll}
\hline$[\mathrm{diol}] \mathrm{mol} \mathrm{dm}^{-3}$ & {$\left[\mathrm{H}^{+}\right], \mathrm{mol} \mathrm{dm}^{-3}$} & $\mathrm{I}, \mathrm{mol} \mathrm{dm}^{-3}$ & $10^{3} \mathrm{k}_{2}, \mathrm{dm}^{3} \mathrm{~mol}^{-1} \mathrm{~s}^{-1}$ \\
\hline 0.396 & 0.5 & 1.0 & 7.62 \\
0.492 & 0.5 & 1.0 & 7.80 \\
0.708 & 0.5 & 1.0 & 7.71 \\
1.008 & 0.5 & 1.0 & 7.62 \\
1.50 & 0.5 & 1.0 & 7.68 \\
0.708 & 0.4 & 1.0 & 6.03 \\
0.708 & 0.6 & 1.0 & 9.63 \\
0.708 & 0.7 & 1.0 & 11.09 \\
0.708 & 0.8 & 1.0 & 13.70 \\
0.708 & 0.5 & 0.6 & 10.18 \\
0.708 & 0.5 & 0.7 & 9.35 \\
0.708 & 0.5 & 0.8 & 8.80 \\
0.708 & 0.5 & 1.10 & 7.74 \\
0.708 & 0.5 & 1.20 & 7.26
\end{tabular}

Table 2: Dependence of Second order rate constant on added anions for oxidation of butane-1,3-diol by $\mathrm{Cr}_{2} \mathrm{O}_{7}{ }^{2-}$ in aqueous $\mathrm{HCl}$ medium at $\left[\mathrm{Cr}_{2} \mathrm{O}_{7}{ }^{2-}\right]=0.01 \mathrm{~mol} \mathrm{dm}^{-3}$, $\lambda_{\max }=580 \mathrm{~nm}$ and $\mathrm{T}=27 \pm 1^{\circ} \mathrm{C}$

\begin{tabular}{|c|c|c|c|c|c|}
\hline $\begin{array}{c}\text { [diol] } \\
\mathrm{mol} \mathrm{dm}_{3}^{-}\end{array}$ & $\begin{array}{c}\operatorname{mol}_{3} \mathrm{dm}^{-} \\
{\left[\mathrm{H}^{+}\right]}\end{array}$ & $\begin{array}{c}\mathrm{I} \\
\mathrm{mol} \mathrm{dm}\end{array}$ & $\begin{array}{l}\mathrm{CH}_{3} \\
\left.\mathrm{COO}^{-}\right] \\
\mathrm{mol}^{-3} \\
\mathrm{dm}^{-3}\end{array}$ & {$\left[\mathrm{HCOO}^{-}\right], \mathrm{mol} \mathrm{dm}^{-3}$} & $\begin{array}{l}10^{3} \mathrm{k}_{2} \\
\mathrm{dm}^{3} \mathrm{~mol}^{-1} \mathrm{~s}^{-1}\end{array}$ \\
\hline 0.708 & 0.5 & 1.0 & 0.05 & - & 6.88 \\
\hline 0.708 & 0.5 & 1.0 & 0.10 & - & 5.92 \\
\hline 0.708 & 0.5 & 1.0 & 0.20 & - & 3.52 \\
\hline 0.708 & 0.5 & 1.0 & 0.35 & - & 1.04 \\
\hline 0.708 & 0.5 & 1.0 & 0.40 & - & 0.27 \\
\hline 0.708 & 0.5 & 1.0 & - & 0.01 & 7.05 \\
\hline 0.708 & 0.5 & 1.0 & - & 0.05 & 6.87 \\
\hline 0.708 & 0.5 & 1.0 & - & 0.10 & 6.41 \\
\hline 0.708 & 0.5 & 1.0 & - & 0.20 & 3.91 \\
\hline 0.708 & 0.5 & 1.0 & - & 0.35 & 2.12 \\
\hline 0.708 & 0.5 & 1.0 & - & 0.40 & 1.48 \\
\hline
\end{tabular}

\section{REFERENCES}

1. Mehrota, R. N., J. Chem. Soc. (1968) 1123.

2. Sankhla, P. S. and Mehrotra, R. N., Indian J. Chem. 10 (1972) 1077.
3. Sankhla, P. S. and Mehrotra, R.N., Indian J. Chem.13 (1975) 904.

4. Prakash, A, Mehrotra, R.N. and Kapour, R.C., J. Chem. Soc. A (1979) 205 . 
5. Mehtra, M., Nagori, R. N. and Mehrota, R. N., J. Chem. Soc. A (1979) 211.

6. Duke, F. R. and Forist, H. A., J. Am. Chem. Soc.2 (1949) 2790.

7. Offner, H. G. and Skoog, D. A., Anal. Chem. 37:B (1965) 1018.

8. Hintz, H. L. and Johnson, D. C., J. Org. Chem.32 (1967) 556.

9. Littler, J. S. and Waters, W. A., J. Chem. Soc. (1960) 2767.

10. Young, L. B. and Trahanovsky, J. Am. Chem. Soc. 91 (1969) 5060.

11. Vogel, I. A., Textbook of Quantitative Inorganic Analysis. $3^{\text {rd }}$ Edition, 1971.

12. Clarke, H. T., A handbook of organic Analysis Qualitative and Quantitative, $5^{\text {th }}$ ed., Edward Arnold Publishers Ltd., London, 1975.

13. Vishnoi, N.K. Advanced Practical Chemistry. $1^{\text {st }}$ ed. Vikas Publishing House PVT Ltd,India.1979.

14. Ayoko, G. A. and Olatunji, M. A. Bull. Chem. Soc. France (1985) 705.

15. Ukoha, P. O., Agunwa U. B. and Okonkwo, E. M. J. Chem. Soc. Nigeria 26:1 (2001) 81.

16. Westheimer, F. H., Chem. Res.3 (1970) 347.

17. Espenson, J. H., Accounts Chem. Res.3 (1970) 347.
18. Schwarzenbach, G. and Meier, J., J. Inorg. Nucl. Chem.8 (1958) 302.

19. Hepler, L. G., J. Am. Chem. Soc. 80 (1958) 6181.

20. Benson, D., Mechanism of Inorganic Reactions in Solution, McGraw - Hill, UK, 1968.

21. Ayoko, G. A., Iyun, J. F. and Okechukwu, R. C. Bull. Chem. Soc. Ethiopia 4:1 (1990) 33.

22. Iyun, J. F., Ayoko, G. A. and Ekubo, A., Indian J. Chem. 31A (1992) 943.

23. Mamman, S. and Iyun, J. F., Nig. J. Chem. Res.9 (2004) 35.

accepted 18/5/05

received 16/2/05 